\title{
LOS ESTUDIOS DE RAFAEL LAPESA SOBRE LITERATURA MEDIEVAL
}

\author{
Miguel Ángel Pérez Priego
}

La contribución de don Rafael Lapesa a los estudios literarios medievales es fundamental, no sólo en sus numerosísimos trabajos publicados, sino en las muchas lecciones y cursos que ha impartido a lo largo de tantos años de magisterio. No ha habido tema, autor ni obra importante de la literatura medieval que no haya merecido su atención de filólogo y crítico, y sobre los que no haya dejado un sabio estudio o comentario y una aportación reveladora. Siguiendo el orden cronológico de los temas, podemos enumerar y comentar algunos de sus principales trabajos.

El descubrimiento de las jarchas y las dificultades de su lectura e interpretación, dio pie a un preciso estudio de Lapesa que, a partir de los libros de Stem y García Gómez, fijaba el texto romance de algunos de aquellos cantarcillos líricos, "Sobre el texto y lenguaje de algunas jarchyas mozárabes", Boletín de la Real Academia Española, 40 (1960), 5;3-65. En directa conexión con ese fondo poético, prestaría también más tarde atención al copioso repertorio de la lírica tradicional y dedicaría una amplia y enjundiosa reseña a la magna obra de Margit Frenk, Corpus de la antigua lírica popular hispánica (siglos XV a XVII) (Madrid, Castalia, 1987), reseña publicada primero en la revista Saber leer, noviembre de 1989, y recogida luego, con el título "El mundo de la antigua lírica popular hispánica", en De Berceo a Jorge Guillén, Madrid, Gredas, 1997, pp. 110-121.

El mundo de la épica, conectado con el romancero, fue estudiado por Lapesa en un documentado artículo sobre "La lengua de la poesía épica en los cantares de gesta y en el romancero viejo", publicado primero en el Anuario de Letras, de México, 4 (1964) y recogido después en su libro De la Edad Media a nuestros días, Madrid, Gredas, 1967, pp. 9-28. En él define y analiza los rasgos más característicos del lenguaje épico, como la presencia de arcaísmos lingüísticos, las fórmulas estereotipadas en epítetos o aposiciones, la variación de tiempos verbales para introducir animación y vivificación en el relato juglaresco, así como singulares libertades en el empleo de formas, construcciones sintácticas y vocabulario. Todos ellos, como dice Lapesa, son procedimientos estilísticos que, asimilados por la comunidad de poetas y oyentes, contribuyen a transformar la obra individual en creación colectiva.

Fiel a las teorías de su maestro Menéndez Pida!, al Cantar de Mio Cid ha dedicado sendos trabajos sobre la lengua y la cronología de la obra, que han frenado seriamente las acometidas de la crítica antipidalista: "Sobre el Cantar de Mio Cid. Crítica de críticas", en Estudios de historia lingüística española, Madrid, Paraninfo, 1984, pp. 11-42 (recoge los artículos publicados anteriormente en Études de Philologie Romane et d'Histoire Littéraire 
offerts à Jules Horrent, Lieja, 1980, 213-231, y en Essays on Narrative Fiction in the Iberian Peninsula in Honour of Frank Pierce, Oxford, 1982, 55-6). Como se sabe, la fecha del cantar cidiano viene siendo cuestión muy debatida en los últimos tiempos y la de 1207, que consta en el éxplicit del manuscrito, ha conseguido una aceptación bastante generalizada, sobre todo, a partir de los trabajos de Ubieto, Pattison, Russell y Smith. Algunos de los argumentos históricos de Ubieto y los lingüísticos de Pattison han sido contestados por Lapesa, quien rechaza el pretendido aragonesismo del poema, al igual que aspectos lingüísticos tenidos por más tardíos, como la presencia de derivados en - $a d a$, - ura, con sentido concreto y no abstracto (arrancada, çelada, apreciadura, cintura), que Pattison entiende no se producen hasta comienzos del siglo XIII, pero que Lapesa documenta desde los siglos X y XI. Del mismo modo, rechaza argumentos históricos, como el de la postura antinobiliaria que refleja el poema, no necesariamente 'burguesa' y más desarrollada en Aragón; el del parentesco del héroe con los reyes de España; el del nombre de Navarra, etc. A pesar de todo, la conclusión de Lapesa es ejemplarmente mesurada: "Carecen, pues, de base las objeciones lingüísticas (...) Admito, sin embargo, que el texto conservado puede contener enmiendas y añadiduras posteriores a 1140, e incluso responder a una refundición. Creo que el texto primitivo sería más dialectal (...) tendría arcaísmos (...) mozarabismos (...) algún aragonesismo (...) Pero desde el punto de vista lingüístico nada aconseja pensar que el Cantar se escribiera en Aragón. Tampoco me inclino a aceptarlo desde el punto de vista histórico (...) No he intentado defender que el texto del Cantar de Mio Cid, tal como hoy lo poseemos, responda sin alteraciones al redactado entre 1140 y $1147 "$.

En los orígenes del teatro, el Auto de los Reyes Magos, con los estudios de Lapesa, "Sobre el Auto de los Reyes Magos: sus rimas anómalas y el posible origen de su autor", en Homenaje a Fritz Krüger, II, Mendoza, 1954, recogido en De la Edad Media a nuestros días, cit., pp. 37-47; y "Mozárabe y catalán o gascón en el Auto de los Reyes Magos", en Miscellània Aramon i Serra, Barcelona, Curial, 1983, 277-94, recogido en Estudios de historia lingüística española, cit., pp. 138-156, ha desvelado algunos de su más enigmáticos misterios, como el del origen de su autor y el enclave toledano de la obra. De la catedral de Toledo, desde época muy antigua, procede el códice en que se conserva el Auto, códice que contiene en latín las glosas al Cantar de los Cantares y a las Lamentaciones de Jeremías, de Gilberto de la Porrée (+1154), quien provocó una extendida controversia sobre el dogma de la Trinidad, rebatida por San Bernardo en el concilio de Reims (1148), cuyas resoluciones fueron asimismo promulgadas en Toledo por el arzobispo don Raimundo. Partiendo de esos datos, Lapesa ha sabido dar una explicación muy plausible del origen material del Auto: "es verosímil que nuestro códice del siglo XII (...) llegase allí al calor del interés suscitado por la polémica. Esto acentúa la posibilidad de que fuese Toledo donde se aprovecharon las dos hojas sobrantes del manuscrito para apuntar el texto del Misterio, que anualmente se representaría en la catedral". En cuanto a la lengua de la obra, ha hecho notar la fuerte influencia franca y ha postulado la procedencia gascona de su autor, posiblemente un gascón toledanizado:

De la magna producción de Alfonso el Sabio, Lapesa ha prestado particular atención a una obra considerada menor, como el Setenario que, tras el análisis de su simbología y valor literario, ha visto realzada su importancia, "Símbolos y palabras en el Setenario de Alfonso X", en In memoriam Raimundo Lida. Nueva Revista de Filología Hispánica, 29 (1980), 247-261, 
recogido en Estudios de historia lingüística española, cit., pp. 226-238. También sobre la obra poética del rey Alfonso ha introducido alguna importante precisión histórico-literaria. Tal es el caso de la breve composición que comienza "Senhora, por amor Dios", la única escrita en castellano de las treinta cantigas profanas que se le atribuyen. En un breve artículo, "¿Amor cortés o parodia? A propósito de la primitiva lírica castellana”, en Estudis de Llatí Medieval $i$ de Filologia Romànica dedicats a la memòria de Lluis Nicolau d'Olwer, Estudis Románics; 2 (1961-1966), recogido en De la Edad Media a nuestros días, cit., pp. 48-52, Lapesa la ha interpretado sagazmente como poema paródico y de burlas, lo que explicaría que en ella haya sido abandonado momentáneamente el uso de la lengua lírica tradicional en favor del castellano.

En el s. XIV, son de decisiva importancia sus trabajos sobre el Libro de buen amor, el Canciller Ayala o un autor menos conocido como Fray Pedro Fernández Pecha. Del Libro de buen amor, ha estudiado particularmente el tema de la muerte, en un clarificador artículo que supone toda una interpretación de la obra, "El tema de la muerte en el Libro de buen amor", en Estudios dedicados a James Homer Herriot, Universidad de Wisconssin, 1966, recogido en De la Edad Media a nuestros días, cit., pp. 53-75. En el tratamiento de ese tema se revela, en efecto, tanto el carácter vitalista de Juan Ruiz, que preside todo el libro, como el profundo desasosiego que le produce el sentimiento de la muerte. De ella ha procurado no tratar en casi todo el transcurso de la obra, pero ahora, cuando muere Trotaconventos, parece que no tiene más remedio que encararla. Sin embargo, aquel sentimiento de repulsa es el que le lleva a hacerlo por medio de un planto paródico que en alguna medida aliviase aquel desasosegado estremecimiento que le producía.

Sobre Pero López de Ayala, escribió un magnífico trabajo de síntesis, que se publicó como capítulo de la Historia General de las Literaturas Hispánicas, dirigida por Guillermo Díaz Plaja, I, Barcelona, 1949, pp. 493-515, y ha sido recogido en el libro De Ayala a Ayala: estudios literarios y estilísticos, Madrid, Istmo, 1988, pp. 9-37. Lapesa estudia la figura del Canciller en un mundo de transición política y social, en el que ve hundirse los valores de la Edad Media y registra nuevas formas de pensamiento y acción que anuncian un espíritu moderno. De igual modo, su obra, escrita pasados ya los cincuenta años, poseerá una profundidad y vigor expresivo que darán animación a la sátira y moralidades del Rimado y, en el caso de las Crónicas, transformarán su carácter de narración medieval dejando paso a trazos de historia psicológica más modernos. En un trabajo posterior, "Las rimas penitenciales del Canciller Ayala: tradición y elemento personal”, en Homenaje a Pedro Sáinz Rodríguez, II, Madrid, Fundación Universitaria Española, 1986, pp. 391-403, recogido en De Ayala a Ayala, cit., pp. 39-54, Lapesa ha analizado también cuatro poemas de carácter penitencial insertos en el Rimado, en los que el Canciller actualiza la tradición espiritual y literaria recibida y la encuadra en circunstancias concretas de su propio existir. Tales poemas resultan así la primera muestra de profunda emoción individual religiosa que aparece en las letras de Castilla.

En cuanto a Fray Pedro Fernández Pecha, fraile alcarreño fundador de la Orden Jerónima, Lapesa le dedicó un revelador artículo, "Un ejemplo de prosa retórica a fines del siglo XIV: los Soliloquios de Fray Pedro Fernández Pecha", publicado en Studies in Honor of Lloyd A. Kasten, Madison, Hispanic Seminary of Medieval Studies, 1975, y recogido en 
Poetas y prosistas de ayer y de hoy, Madrid, Gredos, 1977, pp. 9-24, en el que destacaba su honda religiosidad interior y la artificiosa elaboración estilística de sus Soliloquios. Eran éstos una sorprendente muestra de prosa religiosa, cuajada de recursos retóricos (amplificaciones, paralelismos, similicadencias, antítesis, etc.), que recogía e intensificaba los procedimientos ornamentales que había introducido en la predicación y la lectura la tradición patrística.

Sin duda, el capítulo de la historia literaria medieval que más se ha beneficiado de los estudios de Lapesa y que a partir de ellos ha tenido una mayor renovación crítica, ha sido el de la poesía del siglo XV. La generación de los primeros poetas cortesanos del Cancionero de Baena, fue estudiada en un clarificador artículo sobre la lengua literaria de esos poetas, "La lengua de la poesía lírica desde Macías a Villasandino", Romance Philology, 7 (1953), 51-59, recogido en Estudios de historia lingüística española, cit, pp. 239-248. En él analiza Lapesa el uso que se venía haciendo del gallego como lengua poética por los poetas de la primera generación, su declive cuando la lírica amatoria dejó de ser el género preferido en los primeros lustros del siglo XV, y su retorno ya como deliberado arcaísmo en los poetas de las cortes de Juan II y Alfonso V. Igualmente ha estudiado, de manera sagaz y documentada, las conexiones de la poesía de cancioneros del siglo XV con la poesía italianizante del Renacimiento y la continuidad de muchos de los temas y motivos de aquélla, "Poesía de cancionero y poesía italianizante", en Strenae. Estudios de Filología e Historia dedicados al Profesor Manuel García Blanco. Acta Salmanticensia, 16 (1962), recogido en De la Edad Media a nuestros días, cit., pp. 145-171. En esa línea, ha estudiado la configuración literaria de distintos géneros poéticos o la trayectoria de algún tema mitológico, en trabajos como "Los géneros líricos del Renacimiento: la herencia cancioneresca", en Homenaje a Eugenio Asensio, Madrid, Gredos, 1998, pp. 259-275, recogido luego en De Berceo a Jorge Guillén, cit., pp. 122-145; "Poesía docta y afectividad en las 'consolatorias' de Gómez Manrique", en Estudios sobre Literatura y Arte dedicados al Profesor Emilio Orozco Díaz, II, Universidad de Granada, 1979, pp. 231239, recogido en De Ayala a Ayala, cit., pp. 55-64; "Cartas y dezires o lamentaciones de amor: desde Santillana y Mena hasta don Diego Hurtado de Mendoza", en Symbolae Pisanae. Studi in onore di Guido Mancini, Pisa, Giardini, 1989, pp. 295-310, recogido en De Berceo a Jorge Guillén, cit., pp. 79-97; o "Sobre el mito de Narciso en la lírica medieval y renacentista", en Epos, 4 (1988), pp. 9-20, recogido en De Berceo a Jorge Guillén, cit., pp. 64-77. Asimismo ha estudiado en profundidad la obra de poetas principales, como Santillana, Mena o Imperial. A éste dedicó un trabajo fundamental sobre la cronología de su obras, sus fuentes italianas y el uso del endecasílabo, "Notas sobre Micer Francisco Imperial", en Homenaje a Amado Alonso, Nueva Revista de Filología Hispánica, 7 (1953), recogido en De la Edad Media a nuestros días, cit., pp. 76-94. Por su parte, en "El elemento moral en el Laberinto de Mena: su influjo en la disposición de la obra”, en Joseph E. Gillet. Memorial Volume, Hispanic Review, 27 (1959), recogido en De la Edad Media..., cit., pp. 112-122, estudia el móvil ético como elemento fundamental en la construcción de tan complejo poema. El Laberinto, subraya Lapesa, fue concebido por el poeta como instrumento para que loś caballeros castellanos de la época cobraran conciencia de su glorioso destino y lo sirvieran con el ejercicio de la virtud. Esa moral nobiliaria, destinada a los defensores, a los "potentes" (no se menciona en la obra ni a eclesiásticos ni a gentes humildes), tiene gran importancia en la disposición de la obra en círculos u órdenes ocupadas por personajes virtuosos o viciosos, del pasado y del presente, 
pero cuyo número y nombres son continuamente variados o incluso silenciados, precisamente por esa intencionalidad moral que guía al poeta y le permite dilatar o abreviar, añadir o suprimir conforme al cuadro de valores morales que euiere proponer.

La obra del Marqués de Santillana ha sido la estudiada más intensa y extensamente por Lapesa en una serie sucesiva de trabajos que ha ido desgranando a lo largo de casi treinta años, prueba evidente de la particular preocupación del crítico por la figura del poeta de las serranillas. Ese interés se puso ya de manifiesto al dedicar Lapesa su discurso de ingreso en la Academia a Los decires narrativos del Marqués de Santillana, Madrid, Real Academia Española, 1954, trabajo al que inmediatamente siguieron varios artículos sobre otros aspectos de la obra santillanesca, "Sobre la fecha de la Comedieta de Ponza", Archivum, 4 (1954), 8186, "La cultura literaria activa en la poesía juvenil de Santillana", Atlante, 2 (1954), 119-125, o "El endecasílabo en los sonetos de Santillana", Romance Philology, 10 (1956-57), 180-185, para culminar en la que sigue siendo la mejor monografía sobre la obra del autor, La obra literaria del Marqués de Santillana, Madrid, Ínsula, 1957. Todavía en años posteriores verían la luz trabajos fundamentales sobre obras como los Proverbios, el Bías o las serranillas: "Los Proverbios de Santillana. Contribución al estudio de sus fuentes", Hispanófila, 1 (1957), recogido en De la Edad Media a nuestros días, cit., pp. 95-111; "Un gran poema estoico del Marqués de Santillana”, Ínsula, 12 (1957), 130; Marqués de Santillana, Serranillas, Edición y prólogo, Santander, 1958; "De nuevo sobre las serranillas de Santillana", en Libro-homenaje a Antonio Pérez Gómez, II, Cieza, 1978, 43-50; y "Las serranillas del Marqués de Santillana", en El comentario de textos, 4. Poesía medieval, Madrid, Editorial Castalia (Literatura y Sociedad), 1983, 243-276. Numerosísimas son las aportaciones contenidas en estos trabajos, que nos han devuelto una visión y una valoración de la obra de Santillana mucho más precisa de la que hasta ese momento había establecido la tradición crítica. Sobre las serranillas, por ejemplo, Lapesa nos las ha hecho ver como un interesantísimo ciclo poético perfectamente ordenado en su secuencia artística y variado en sus rasgos estilísticos. De las canciones y decires, ha establecido con nitidez su originalidad literaria, muchas veces respecto de sus modelos franceses o italianos. En el caso de los sonetos, Lapesa ha establecido una segura cronología y ha dado las razones y los porqués del que fue todavía un intento inmaduro por parte del poeta medieval. De los Proverbios, ha rastreado la extraordinaria diversidad de fuentes, que van desde la Biblia, el Flos sanctorum o San Agustín, a historiadores clásicos como Tito Livio y Valerio Máximo, poetas como Ovidio, Lucano y Estacio, y sobre todo los escritos morales de Cicerón y Séneca, aparte de repertorios medievales como el Breviloquium de quatuor virtutibus de John Waleys o el De vita et moribus philosophorum de Walter Burley, y las ha valorado, más que como preocupación filológica y humanística, como una síntesis cultural y ejemplar. El Bías contra Fortuna nos lo ha sabido mostrar Lapesa como un poema de alta calidad literaria, una exposición poética de moral estoica, aprendida en las obras de Séneca, pero también en el De remediis utriusque Fortunae de Petrarca, que en muchos de sus postulados se contrapone a la moral cristiana (la sola virtud como bien supremo o la justificación del suicidio) y en otros va incluso más allá de la filosofía del Pórtico (la esperanza de una vida futura), con todo lo cual supone un gran esfuerzo por recrear una ideología puramente pagana, al margen de la cristiana en que estaban inmersos el autor y su época. 
A la prosa del siglo XV ha dedicado también Lapesa distintos trabajos. Uno temprano fue el dedicado a "El lenguaje del Amadís manuscrito", publicado en el Boletín de la Real Academia Española, 36 (1956), pp. 219-225, en el que analiza algunos rasgos lingüísticos de los fragmentos de la obra hallados por Rodríguez Moñino, que sitúa cronológicamente en torno a 1420. A figura tan interesante como Juan de Lucena, dedicó el estudio "Sobre Juan de Lucena: escritos suyos mal conocidos o inéditos", en Collected Studies in honor of Américo Castro's Eightieth Year, Oxford, 1965, recogido en De la Edad Media..., cit, pp. 123-144, en el que analiza aspectos del sentir y pensar de Lucena en los que se refleja la crisis del converso al tratar de insertarse en la sociedad dominante (adhesión a las formas de piedad íntima, crítica al poder temporal de la Iglesia, sentido del pro común, sátira antiseñorial, amargo pesimismo, dudas ante la inmortalidad del alma). Reconstruye también allí los fragmentos de un escrito en defensa de los judíos, que fue duramente atacado por el canónigo Alfonso Ortiz y que no se ha conservado, y publica un breve tratado de Lucena sobre el origen y preeminencias del oficio de los heraldos, hasta entonces inédito, escrito en un estilo retórico y latinizante y en el que fantasea el autor con nombres y mitos de la antigüedad.

La Celestina ha sido también objeto de estudio para Lapesa. Aparte de dos extensos comentarios a los clásicos trabajos sobre la obra por parte de Ma Rosa Lida de Malkiel y de Américo Castro, ha dedicado a la inmortal obra un penetrante artículo titulado "En torna a un monólogo de Calisto", publicado en el Homenaje a Aranguren (1972) y recogido en Poetas y prosistas de ayer y de hoy, Madrid, Gredos, 1977, 73-91. En él profundiza Lapesa en el estudio de los personajes y en especial en el de Calisto. Advierte cómo ya en el acto I están trazados con aguda penetración en sus almas complejas y contradictorias, pero cómo Fernando de Rojas ahondará todavía mucho más en los caracteres motivando gradualmente su transformación íntima. El caso de Calisto es muy revelador, pues del amante irresoluto y anulado por la pasión del acto I, pasa a ser un personaje mucho más complejo, como se manifiesta particularmente en sus dos monólogos paralelos de los actos XIII y XIV. En este último sobre todo se advierte una marcada complejidad psicológica y un mayor juego de autoanálisis y autosugestión, debatiéndose el personaje entre los deberes sociales de la honra y el valor que reconoce al placer gozado.

Como hemos podido comprobar en este somero recorrido, Lapesa ha revisado casi todos los capítulos de la literatura española de la Edad Media. Lo ha hecho con la sabiduría del filólogo y con la sensibilidad del verdadero humanista. Los problemas críticos los ha enfocado, primero, desde el rigor de la crítica textual y el profundo conocimiento de la historia de la lengua, para remontarse, después, a los más perspicuos análisis de temas, géneros y estilo. Nos ha ofrecido con ello una visión de los estudios filológicos en toda su amplitud y complejidad, pero también en toda su riqueza y profundidad humana. Porque el profesor Lapesa ha trascendido siempre la frialdad de la letra y ha buscada desentrañar los comportamientos del alma humana desde las formas creativas. Como él mismo ha dicho, resumiendo en pocas palabras su inmensa y ejemplar dedicación: "No tengo fe ni esperanza en los análisis que pretenden comprender creaciones literarias prescindiendo del creador respectivo; por eso prefiero seguir manteniéndome en la línea de las humanidades no deshumanizadas". 